\title{
OSTEOCHONDRITIS DISSECANS AND OTHER LESIONS OF THE FEMORAL CONDYLES
}

\author{
J. BRADLEY, D. J. DANDY
}

From Newmarket General Hospital and Addenbrooke's Hospital, Cambridge

\begin{abstract}
We reviewed lesions of the femoral condyles seen in 5,000 knee arthroscopies, recording the findings and the age and sex of the patients. We were able to distinguish the characteristics of developing and late osteochondritis dissecans, acute and old osteochondral fractures, chondral separations, chondral flaps and idiopathic osteonecrosis, and suggest that these are separate distinct conditions. Haemarthrosis was associated only with acute osteochondral fractures.

The characteristic feature of osteochondritis dissecans was an expanding concentric lesion at the 'classical' site on the medial femoral condyle which appeared during the second decade of life and progressed to a concave steep-sided defect in the mature skeleton. Caffey's (1958) classification of epiphyseal dysplasias could not be applied to osteochondritis dissecans, which appeared to have a gradual onset without acute trauma. Much of the controversy about the cause of osteochondritis dissecans is the result of imprecise nomenclature.
\end{abstract}

Many papers have been written about osteochondritis dissecans but the subject remains controversial. Clanton and DeLee (1982) distinguished two groups of patients with osteochondritis dissecans, one of children under the age of 15 and one of adults up to the age of 50 years. Smillie (1960) described four patterns of osteochondritis dissecans, including an adult form appearing after epiphyseal closure, but Green and Banks (1953) reported the condition only in children.

Many different causes have been suggested. These include trauma (Aichroth 1971), contact with the tibial spine (Fairbank 1933), abnormal ossification of the epiphyseal cartilage (Caffey et al. 1958; Langer and Percy 1971), hereditary influences and generalised disorders such as multiple epiphyseal dysplasia and Fröhlich's syndrome (Ribbing 1955; Smillie 1960; Smith 1960; Phillips and Grubb 1985). The role of trauma is particularly controversial. Both Paget (1870), in the first description of the condition, and König (1887) who first used the term 'osteochondritis dissecans' in a report of

J. Bradley, FRCS, Senior Orthopaedic Registrar

Addenbrooke's Hospital, Hills Road, Cambridge CB2 2QQ, England.

D. J. Dandy, FRCS, Consultant Orthopaedic Surgeon

Newmarket General Hospital, Exning Road, Newmarket, Suffolk CB8 7JG, England.

Correspondence should be sent to Mr D. J. Dandy.

(c) 1989 British Editorial Society of Bone and Joint Surgery $0301-620 X / 89 / 3111 \$ 2.00$

J Bone Joint Surg [Br] 1989;71-B:518-22. eight patients with a definite history of minor injury, believed that trauma could not have been the sole cause. Aichroth (1971) found a history of significant trauma in $46 \%$ of his patients.

The explanation for these differences may be imprecise usage of the term 'osteochondritis dissecans'. This is often used loosely to describe any condition in which there is separation of bone or articular cartilage from the underlying femoral condyle. Aichroth (1971), describing 100 patients with osteochondritis dissecans, included seven with osteochondral fractures, some with radiological abnormalities of ossification and some which, in retrospect, were probably the result of osteochondral fractures caused by patellar dislocation. As Barrie (1987) has pointed out so eloquently, König had an ear for a euphonious title, and the harmony of the words has led the profession to abuse the diagnosis.

To help resolve some of the differences of opinion, we have attempted to distinguish between several disorders sometimes considered with osteochondritis dissecans and to identify their incidence, age distribution, and characteristics.

\section{PATIENTS AND METHODS}

The incidence, age and sex distribution of different lesions of the femoral condyle was determined in 5,000 consecutive arthroscopic examinations by one surgeon (DJD) in a predominantly elective practice during an 11year period. 
The indications for arthroscopy were persistent mechanical symptoms and unexplained effusion, in the absence of a diagnosis, or difficulty in deciding management. Arthroscopy was never performed solely for the investigation of asymptomatic radiological abnormalities, or if the investigation was unlikely to have any immediate benefit for the patient. Many patients were managed without arthroscopy and the figures do not represent the total number of patients with lesions of the femoral condyles seen during the study period.

Definition of the different conditions. Acute and old osteochondral fractures, chondral separations, chondral flaps and spontaneous osteonecrosis were considered to be the lesions most often confused with osteochondritis dissecans. We identified lesions by the following criteria (Fig. 1).
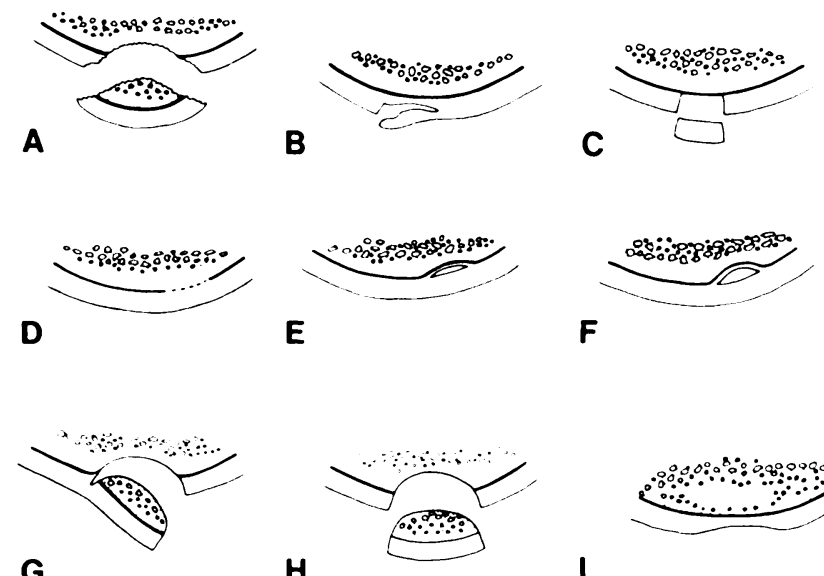

G

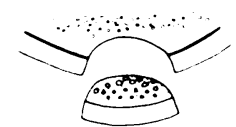

H

Fig. 1 separations (Johnson-Nurse and Dandy 1985). Both longitudinal and circular separations were included for the purposes of this study, but old injuries and patients with extensive degenerative change were not included and lesions less than $5 \mathrm{~mm}$ wide in any direction were disregarded.

Chondral flaps. Patients with isolated lesions involving only part of the thickness of the articular cartilage (1B) were considered to have chondral flaps (Johnson-Nurse and Dandy 1985). Again, lesions less than $5 \mathrm{~mm}$ across were disregarded and patients with degenerative change on the affected condyle were not included.

Osteochondritis dissecans. Two patterns of osteochondritis dissecans were recognised: developing lesions and late lesions.

Developing lesions of osteochondritis dissecans were recognised as those in which a single area of ossification had developed separately from the main body of an otherwise normal epiphysis (ID, E, F). Early radiographs showed only an irregularity in the ossifying margin of the epiphysis (Caffey et al. 1958; Type II) but later radiographs showed a separate concentric flake of bone (Caffey Type III) which grew at the same rate as the epiphysis but remained separated from it by a transradiant line. Neither the fragment nor the defect were corticated. Patients with irregular or patchy calcifications of the epiphysis (Caffey Type I), consistent with epiphyseal dysplasia, were not included in this group.

Late osteochondritis dissecans was diagnosed in patients with loose bodies which had arisen from a concave defect on the femoral condyle with steeply sloping edges $(1 \mathrm{G}, \mathrm{H})$. The shape of these defects distinguished them from the flat sites of origin of osteochondral fractures. Both the fragment and the base of the condylar lesion were corticated with no exposed cancellous bone. Some patients whose radiographs showed a corticated fragment lying in situ in a condylar defect were found at arthroscopy to have intact articular cartilage over the lesion. This lesion was also diagnosed as late osteochondritis dissecans.

Idiopathic osteonecrosis. Patients in whom the disappearance of subchondral bone had left a cavity roofed by a plate of cortical bone (1I) were considered to have idiopathic osteonecrosis (Bauer 1978). At arthroscopy, the cortical plate was found to be unstable, and the cavity contained soft amorphous tissue which blended with the underlying bone without a corticated base. Patients with rheumatoid arthritis and other conditions associated with osteonecrosis were excluded from this category.

Other conditions. In addition to the conditions listed above, patients with steroid-induced osteonecrosis and epiphyseal dysplasia were seen during the study period, but were usually managed without arthroscopy.

Steroid osteonecrosis. Patients who had received large doses of corticosteroids following transplantation or for other reasons were seen with separating fragments 
involving large segments of the femoral condyle, sometimes the whole condyle. These patients often had lesions of the femoral head as well. Both knees of two patients were examined arthroscopically.

Epiphyseal dysplasia. Patients with irregular ossification of the growing epiphysis other than the appearances described above were considered to have epiphyseal dysplasia and the lesions were not subdivided for the purpose of this study. Only those patients who had an effusion or mechanical symptoms of locking or catching underwent arthroscopy. Two such knees were arthroscoped during the study period.

\section{RESULTS}

Table I shows the incidence and sex distribution of the different conditions and Figure 2 shows the age distribution. The incidence of haemarthrosis and of intact articular cartilage is also shown.

Acute osteochondral fractures. All patients with acute osteochondral fractures had a haemarthrosis and a definite history of recent injury. All patients with a haemarthrosis included in the study had acute osteochondral fractures. the lesions of degenerative osteoarthritis. Fragments of articular cartilage from chondral separations not visible radiologically were sometimes identified arthroscopically and removed but in others, the chondral fragment had become fragmented and remained as particulate debris within the joint.

Osteochondritis dissecans. The lesions of developing and late osteochondritis dissecans were found only at the 'classical' site on the medial femoral condyle. Careful search was made for these lesions at other sites on the condyles but none were found.

Developing osteochondritis dissecans. The lesions of developing osteochondritis dissecans were seen only in patients in their second decade, and the articular cartilage was intact in all patients under the age of 18 years. All had presented with pain and none had a haemarthrosis. The site of the radiological lesion could be identified and probed at arthroscopy in all knees. One patient had lesions in both knees.

Late osteochondritis dissecans. The lesions of late osteochondritis dissecans were not seen in patients under the age of 18 years. In some, the fragment had separated from its bed but remained attached by a bridge of articular cartilage. Four patients had lesions in both

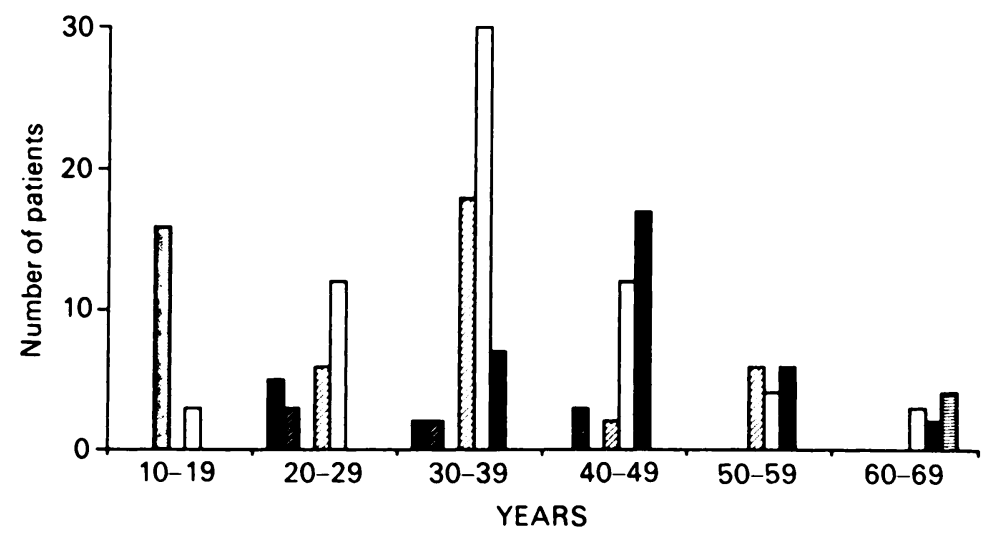

Acute osteochondral fractures Old osteochondral fractures Developing osteochondritis dissecans [.] Late osteochondritis dissecans

Fig. 2

The age distribution of osteochondral lesions of the femoral condyle.

Old osteochondral fractures. No difficulty was encountered in distinguishing between old osteochondral fractures and late osteochondritis dissecans using the criteria given above. One patient had lesions in both knees. Chondral separations and chondral flaps. Only recent lesions with clean, sharp margins in otherwise normal condyles were included to avoid difficulty in distinguishing between old chondral separations, chondral flaps and knees; the articular cartilage over the lesion was intact in two patients.

Idiopathic osteonecrosis. Idiopathic osteonecrosis was easily distinguished from the other conditions by the bone loss and absence of cortication which was visible radiologically and arthroscopically.

Steroid osteonecrosis. The lesions of steroid osteonecrosis differed from those of osteochondritis dissecans and 
osteochondral fractures in the shape and size of the fragment, as well as the history of steroid administration. The fragments were large, corticated, irregular and involved large segments of the femoral condyle.

Epiphyseal dysplasia. Epiphyseal changes were seen in association with a discoid meniscus in one patient (Glasgow, Aichroth and Baird 1982), but no patient with a discoid meniscus was found to have osteochondritis dissecans. In a second patient, a lesion of the lateral femoral condyle was drilled percutaneously with satisfactory results but it is not known whether the drilling influenced the natural history of the lesion.

\section{DISCUSSION}

Our main purpose was to attempt to define osteochondritis dissecans and separate it from other conditions. Differentiation between osteochondritis dissecans and acute osteochondral fractures was straightforward. All patients seen with an acute osteochondral fracture had a haemarthrosis, but a haemarthrosis was not found with any other condition. The appearances of the lesions were also different. Fragments from old osteochondral fractures were recognised by the characteristic shape, with one flat and one convex surface. The flat sites of origin commented: "but how can such pieces of articular cartilage be detached from bone? They cannot be chipped off; no force can do this".

Caffey et al. (1958) studied the radiological appearances of the growing epiphysis in a group of asymptomatic knees, but only one of their patients met our criteria for osteochondritis dissecans, and it is relevant that this patient was the only one who later developed symptoms. This fact, and the difficulty in placing cases of osteochondritis dissecans consistently into any one of the Caffey types suggests that this classification is not applicable to osteochondritis dissecans.

We suggest that the diagnostic criterion for developing osteochondritis dissecans is an expanding concentric lesion at the margin of an otherwise normal epiphysis. The only lesions which met this criterion were found in the medial femoral condyle, at the classical site, and during the second decade of life. No such lesions were seen at other sites on the condyles in our 11-year and 5,000-patient series, although four were seen on the patella. Similarly, the characteristic steep-sided defects of late osteochondritis dissecans were found only after skeletal maturity and at the classical site.

We conclude from these findings that the lesion that we call developing osteochondritis dissecans later be-

Table I. Details of patients

\begin{tabular}{|c|c|c|c|c|c|c|c|}
\hline & \multicolumn{2}{|c|}{$\begin{array}{l}\text { Osteochondral } \\
\text { fracture }\end{array}$} & \multicolumn{2}{|c|}{$\begin{array}{l}\text { Osteochondritis } \\
\text { dissecans }\end{array}$} & \multicolumn{2}{|c|}{ Chondral injury } & \multirow{2}{*}{$\begin{array}{l}\text { Spontaneous } \\
\text { necrosis }\end{array}$} \\
\hline & Acute & Old & Developing & Late & Separation & Flaps & \\
\hline Number of knees & 7 & 8 & 16 & 42 & 64 & 32 & 5 \\
\hline Male/female & $4 / 3$ & $8 / 0$ & $13 / 6$ & $37 / 5$ & $52 / 12$ & $21 / 11$ & $4 / 1$ \\
\hline $\begin{array}{l}\text { Age in years } \\
\text { Mean } \\
\text { Range }\end{array}$ & $\begin{array}{l}19.1 \\
16 \text { to } 22\end{array}$ & $\begin{array}{l}34.9 \\
26 \text { to } 49\end{array}$ & $\begin{array}{l}13.6 \\
11 \text { to } 18\end{array}$ & $\begin{array}{l}28.1 \\
18 \text { to } 41\end{array}$ & $\begin{array}{l}32.3 \\
16 \text { to } 67\end{array}$ & $\begin{array}{l}45.6 \\
34 \text { to } 67\end{array}$ & $\begin{array}{l}67 \\
63 \text { to } 75\end{array}$ \\
\hline Haemarthrosis & 7 & 0 & 0 & 0 & 0 & 0 & $\mathbf{0}$ \\
\hline $\begin{array}{l}\text { Intact articular } \\
\text { cartilage }\end{array}$ & 0 & 0 & 16 & 2 & 0 & 0 & 0 \\
\hline
\end{tabular}

were consistent with a tangential injury; they differed markedly from the defects of osteochondritis dissecans.

The ages of the patients with developing or late osteochondritis dissecans were substantially different from those of the patients with osteochondral fractures in this study, and those previously described (Matthewson and Dandy 1978). These differences in age distribution support the proposition that osteochondral fractures and osteochondritis dissecans are separate entities.

Our findings suggest strongly that osteochondral fractures are the result of acute trauma and not a 'dissecting' pathological process. We agree with Paget (1870) who believed that osteochondritis dissecans was a separate condition from osteochondral fractures and comes one of late osteochondritis dissecans, and that any mobile fragments attached at their periphery by articular cartilage represent the separation of an osteochondritic fragment from its bed.

Chondral separations, chondral flaps, steroid osteonecrosis and idiopathic osteonecrosis were easily distinguished from osteochondritis dissecans. The arthroscopic appearance and age distribution of each condition were different, and we consider that these lesion are separate both from each other and from osteochondritis dissecans. We are aware that lesions seen on the lateral femoral condyle are sometimes associated with loose fragments but the appearance and natural history of these differ from osteochondritis dissecans. 
The patients meeting our criteria correspond closely with those described by Paget (1870), by König as category 3 patients and by Green and Banks (1953). We suggest that the recent use of 'osteochondritis dissecans' as a generic term for all disorders in which fragments become separated from the femoral condyles either radiologically or mechanically has made discussion needlessly complicated and should be discontinued.

No benefits in any form have been received or will be received from a commercial party related directly or indirectly to the subject of this article.

\section{REFERENCES}

Aichroth P. Osteochondritis dissecans of the knee: a clinical survey. $J$ Bone Joint Surg [Br] 1971 :53-B:440-7.

Bauer GCH. Osteonecrosis of the knee. Clin Orthop 1978;130:210-7.

Barrie HJ. Osteochondritis dissecans 1887-1987: a centennial look at König's memorable phrase. J Bone Joint Surg [Br] 1987:69-B :693-5.

Caffey J, Madell SH, Royer C, Morales P. Ossification of the distal femoral epiphysis. J Bone Joint Surg [Am] 1958;40-A :647-54.

Clanton TO. DeLee JC. Osteochondritis dissecans: history, pathophysiology and current treatment concepts. Clin Orthop 1982:167:50-64.
Fairbank HAT. Osteo-chondritis dissecans. Br J Surg 1933;21:67-82.

Glasgow MMS, Aichroth PM, Baird PRE. The discoid lateral meniscus: a clinical review. J Bone Joint Surg [Br] 1982:64-B:245.

Green WT, Banks HH. Osteochondritis dissecans in children. $J$ Bone Joint Surg $[\mathrm{Am}]$ 1953;35-A :26-47.

Johnson-Nurse C, Dandy DJ. Fracture-separation of articular cartilage in the adult knee. J Bone Joint Surg [Br] 1985:67-B:42-3.

König. Ueber freie Körper in den Gelenken. Deutsche Ztschr. f. Chir., Leip:. 1887-1888:27:90-109.

Langer F, Percy EC. Osteochondritis dissecans and anomalous centres of ossification: a review of 80 lesions in 61 patients. Can J Surg $1971: 14: 208-15$.

Matthewson MH, Dandy DJ. Osteochondral fractures of the lateral femoral condyle: a result of indirect violence to the knee. $J$ Bone Joint Surg [Br] 1978:60-B:199-202.

Paget J. On the production of some of the loose bodies in joints. St Bartholomew's Hosp Reports 1870;6:1-4.

Phillips HO IV, GrubbSA. Familial multiple osteochondritis dissecans: report of a kindred. J Bone Joint Surg [Am] 1985:67-A :155-6.

Ribbing S. The hereditary multiple ephipyseal disturbance and its consequence for the aetiogenesis of local malacias - particularly osteochondrosis dissecans. Acta Orthop Scand 1955;24:286-99.

Smillie IS. Osteochondritis dissecans: loose bodies in joints: etiology, pathology, treatment. Edinburgh etc: E \& S Livingstone, 1960.

Smith AD. Osteochondritis of the knee: a report of three cases in one family and a discussion of the etiology and treatment. J Bone Joint Surg $[\mathrm{Am}] 1960: 42-\mathrm{A}: 289-94$. 